\title{
Iron Deficiency As A Risk Factor for First Episode of Febrile Seizure
}

\author{
Dr Sunil Kumar Singh ${ }^{1}$, Dr Shashank Shekhar ${ }^{2}$, Dr Rajeeva Mishra ${ }^{3}$ \\ ${ }^{1}$ junior Resident, ${ }^{2}$ junior Resident, ${ }^{3}$ Associate Professor \\ Department Of Pediatrics And Neonatology, Rajendra Institute Of Medical Sciences, Ranchi, Jharkhand India
}

\begin{abstract}
Background: Febrile seizures (FS) are a form of acute symptomatic seizures. They occur in $2 \%$ to $5 \%$ of children and are the most common form of childhood seizures. In the past, it was believed that most FS represented a form of epilepsy and that prognosis was not favorable. FS was believed to cause brain damage and subsequent epilepsy.

Objective: To study the incidence of IDA in febrile convulsion(first episode) and evaluate iron deficiency anemia as a risk factor for febrile convulsion.

Material And Methods: The study will be a case control prospective study conducted on all children with first febrile seizures and febrile illnesses in Pediatrics Intensive Care Unit and Pediatrics Wards of RAJENDRA Institute Of Medical Sciences,Ranchi from May 2014 to June 2015. Cases and Controls are comprised of children with FS and children with febrile illness, respectively. The blood samples from the 50 children comprising the cases and 50 children comprising the controls constituted the material for the study
\end{abstract}

Results: Out of 50 childrens of Febrile Seizure, 29(58\%) childrens were diagnosed having IRON DEFICIENCY Anemia.

Conclusions: IDA was more frequent among children with FS than those with febrile illness alone. The result suggests that IDA may be a risk factor for FFS. Screening for IDA should be considered in children with FFS and iron supplementation shoud be given.

Keyword: Febrile seizure(FS), Iron deficiency anemia(IDA)

\section{Introduction}

Febrile seizures (FS) are a form of acute symptomatic seizures. They occur in $2 \%$ to $5 \%$ of children and are the most common form of childhood seizures. In the past, it was believed that most FS represented a form of epilepsy and that prognosis was not favorable. FS was believed to cause brain damage and subsequent epilepsy. Over the past 25 years, much more information on FS has accumulated from both human and animal studies. The prognosis for FS usually has been found to be good. Such seizures are not associated with any detectable brain damage and epilepsy will eventually develop in only a small minority of children who have had FS $^{7}$. A FS is defined by the International League Against Epilepsy (ILAE) as a seizure occurring in association with a febrile illness (FI) in the absence of a Central Nervous System (CNS) infection or acute electrolyte imbalance in children older than 6 month of age without prior afebrile seizures.

\section{Methodology}

This study was done on 50 confirmed case of febrile seizure diagnosed on the basis of history, clinical examination, family history ,serum electrolyte and age group 6 month to 60 month and 50 control group having fever and there was no episode of seizure in same age group attending inpatient ward ,Department of Pediatrics and Neonatology, Rajendra Institute of Medical Sciences, Ranchi., during the period of april 2015 to march 2016 Cases and Controls are comprised of children with FS and children with febrile illness, respectively. The blood samples from the 50 children comprising the cases and 50 children comprising the controls constituted the material for the study.

The Cases

\section{Inclusion Criteria}

- Aged between 6 months to 6 years

- First febrile seizures( Febrile seizures being defined as a seizure occurring in association with a febrile illness, in the absence of CNS infection or any other defined cause of seizur

\section{Exclusion Criteria}

- Children with previous febrile seizures

- Neurological infections

- Developmental delay 
- Children on Iron therapy

The Control Group

It will include 50 children aged 6 months to 6 years who get admitted with febrile illness without febrile seizures.

All children included in the study will have the following done: Demographic data, seizure details, nature of febrile illness, family history of epilepsy/ febrile seizures, temperature at admission and nutrition status will be recorded and protein energy malnutrition will be graded as per the IAP classification. Estimation of hemoglobin, red blood cell indices and plasma ferritin will be done. Iron deficiency anemia will be defined as 1.hemoglobin $<11 \mathrm{~g} / \mathrm{dl}$,

2.MCV $<70 \mathrm{fl}$,

3.MCH $<27 \mathrm{pg}$

4.Plasma ferritin $<12 \mathrm{~g} \mu \mathrm{gm} / \mathrm{dl}$

\section{Results}

A total of 50 cases of First Febrile Seizure and 50 controls of Febrile illness were analyzed

Table 1: Mean values of various blood parameters:

\begin{tabular}{|l|c|c|c|}
\hline \multicolumn{1}{|c|}{ Parameters } & Ca & Controls & P value \\
\hline Hemoglobin & $8.92 \pm 1.18$ & $9.55 \pm 0.96$ & $<0.001$ \\
\hline $\mathrm{MCV}$ & $67.03 \pm 15.63$ & $84.12 \pm 13.78$ & $<0.001$ \\
\hline $\mathrm{MCH}$ & $30.60 \pm 13.81$ & $37.32 \pm 9.57$ & 0.006 \\
\hline
\end{tabular}

- The mean value for $\mathrm{Hb}$ in cases was $8.92 \pm 1.18$ and in controls was 9.55 \pm 0.96 .

- The mean value for MCV in cases was $67.03 \pm 15.63$ and in controls was 84.12 \pm 13.78 .

- The mean value for $\mathrm{MCH}$ in cases was $30.60 \pm 13.81$ and in controls was 37.32 \pm 9.57 .

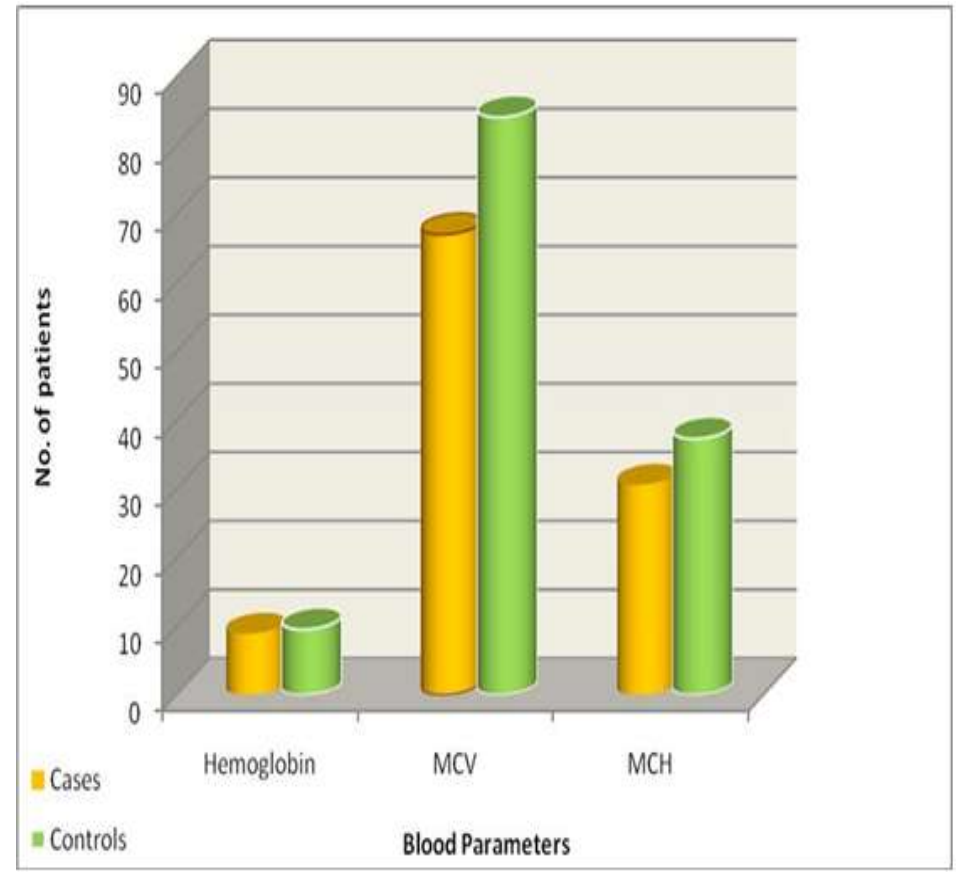

Graph 1: Cases Vs Controls Of Various Blood Parameters 


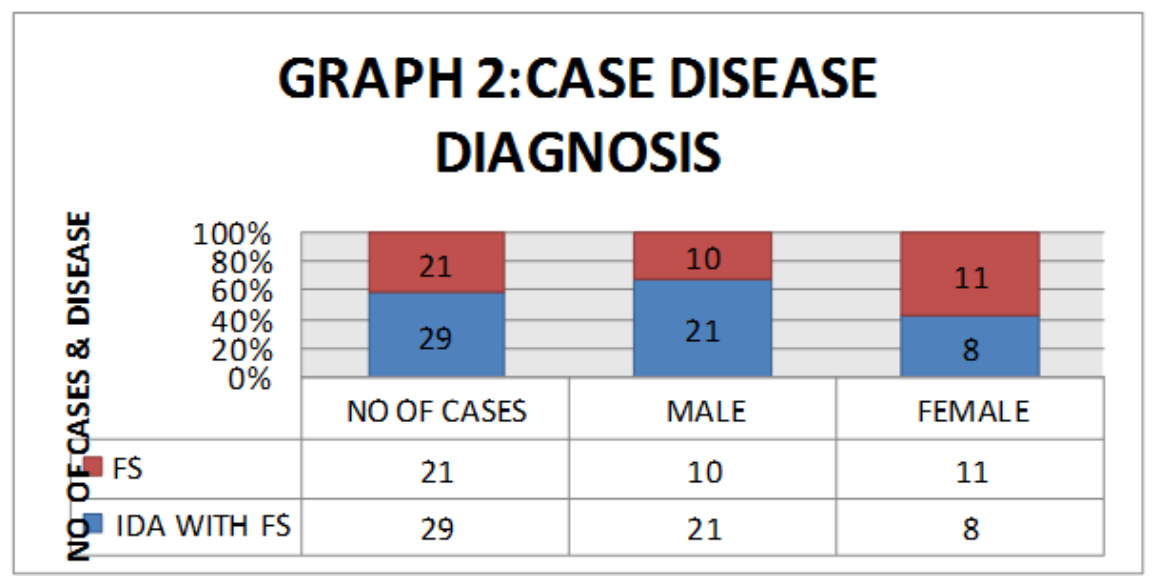

- $58 \%$ cases were diagnosed as IDA with FS were present in the study.

- $18 \%$ controls were diagnosed as IDA with FI in this study.

- $21 \%$ cases of FS were present in the current study.

- $41 \%$ controls were diagnosed as others.

\section{Discussion}

The mean age of onset in present study is 24 months which is comparable to the other studies. Alfredo Piscane et al found the mean age for FS was 15 months. Separate studies done by Vasvani RK et al, Waruiru C et al and Azhar S Daoud et al also found that FS peaks at 18 months. Naveed-ur-Rehmann et al found mean age was22.97 9.52 months. Ellenberg et al found the average convulsion age to be 23.3 months. Amir Salari et al found average age of $39 \pm 15.92$ months. It is generally noted that the febrile convulsion and the first febrile convulsion are more common in second year.

The diagnostic threshold that was employed in present study for Iron deficiency were $\mathrm{Hb}$ level $<11 \mathrm{~g} / \mathrm{dl}$, Among the RBC indices
1. $\mathrm{MCV}<70 \mathrm{fl}$
2. $\mathrm{MCH}<27 \mathrm{pg}$
3. Plasma Ferritin $<12 \mu \mathrm{g} / \mathrm{d}$
4. TIBC $>450 \mu \mathrm{g} / \mathrm{dl}$
5. Transferrin $<250 \mathrm{mg} / \mathrm{dl}$

Table 2: Comparison of serum Iron, TIBC Level between cases and controls

\begin{tabular}{|c|c|c|c|}
\hline \multirow[t]{2}{*}{$\begin{array}{l}\text { ( } \\
\square\end{array}$} & Mean & SD & Level of significance \\
\hline & & & $p$-value \\
\hline FS cases: & 77.65 & 44.7 & 0.037 \\
\hline FI-Control: & 95.2 & 38.08 & \\
\hline TIBC & & & \\
\hline FS cases: & 434.86 & 125.18 & 0.001 \\
\hline FI-control: & 354.14 & 103.1 & \\
\hline
\end{tabular}

Although the most clinically obvious consequence of ID is anemia, but virtually every organ system is affected, resulting in changes in cognitive and behavioral performance, impaired physical growth, and impairment of immune function. Iron deficiency is associated with neurological problems in young children, including developmental delay, stroke ${ }^{14}$, breath-holding spells and pseudotumor cerebri.

In present study, there was variation of the iron level with FS and FI group. Fever, was present in all patients in the both groups. Therefore differences in iron level between the two groups cannot be explained by fever per se. Pisacane et al studied the serum iron level only, between 6- 24 months of age, where the level was low in febrile children. Bidabadi et al reported that the serum Iron level in febrile seizure was higher at a statistically insignificant level. Khalid $\mathrm{N}$ et al couldn't appreciate significante changes ${ }^{16}$. 
Table 3: Comparison of various blood parameter in different studies ${ }^{17}$

\begin{tabular}{|c|c|c|c|c|c|c|c|c|}
\hline Study & $\begin{array}{l}\begin{array}{l}\text { Age } \\
\text { (mths) }\end{array} \\
\end{array}$ & $\begin{array}{l}\mathrm{Hb} \\
(\mathrm{gm} \%)\end{array}$ & $\begin{array}{l}\text { MCV } \\
\text { (fl) }\end{array}$ & $\begin{array}{l}\text { MCH } \\
\text { (pg) }\end{array}$ & $\begin{array}{l}\text { PF } \\
(\mu \mathrm{g} / \mathrm{dl})\end{array}$ & $\begin{array}{l}\text { S.Fe } \\
(\mu \mathrm{g} / \mathrm{dl})\end{array}$ & $\begin{array}{l}\text { TIBC } \\
(\mu \mathrm{g} / \mathrm{dl})\end{array}$ & $\begin{array}{l}\text { S Transf. } \\
\text { (mg/dl) }\end{array}$ \\
\hline Present study & $9-39$ & 8.92 & 67.03 & 30.6 & 45 & 77.65 & 434.86 & 248.6 \\
\hline Pisacane et al & $6-24$ & 10.5 & $<70$ & & $<5$ & - & - & - \\
\hline Daoud et al & $3-72$ & $<11$ & $<72$ & $<24$ & $<30$ & - & - & - \\
\hline $\begin{array}{l}\text { Naveed-ur and } \\
\text { Billoo et al }\end{array}$ & 8-36 & $<10$ & $<70$ & $<24$ & $<10$ & - & - & - \\
\hline Vasvani et al & $8-27$ & 9 & 73.4 & 21.4 & 31.9 & - & - & - \\
\hline Khalid $\mathrm{N}$ et al & $13-18$ & $\begin{array}{l}8.2- \\
9.6\end{array}$ & $55-63$ & $8-14$ & - & - & $438-575$ & - \\
\hline Kobrinsky et all & $6-36$ & $<11$ & $<72$ & $<24$ & $<20$ & - & - & - \\
\hline
\end{tabular}

Note: Mnths- Months; Hb - Hemoglobin; MCH- Mean corpuscular hemoglobin;MCV- Mean cell volume; PF- Plasma Ferritin; S.Fe- Serum Iron; TIBC- Total Iron Binding Capacity; S. Transf- Serum Transferrin

\section{Conclusion}

The association between iron deficiency anemia and febrile seizures has been studied before without any conclusive reports and this study was done for further confirmation. None the less, selection bias as well as confounding by social class does not seem likely in this study.IDA was more frequent among children with FS than those with febrile illness alone ${ }^{15}$. The result suggests that IDA may be a risk factor for FFS. Screening for IDA should be considered in children with FFS. Fever can worsen the negative effect of anemia or for iron deficiency on the brain and a seizure can occur as a consequence. Alternatively, anemia can be associated with the severity of a febrile illness, and more severe cases could be more likely to get seizures.All the investigations carried out to evaluate iron deficiency anemia were significantly lower in cases as compared to controls. This suggests that iron deficient children are more prone for febrile seizures.

\section{References}

[1]. Lennox WG. Significance of febrile convulsions. Pediatrics 1953;11:341

[2]. Livingstone S, Bridge EM, Kajdi L. Febrile convulsions: A clinical study with special reference to heredity and prognosis. J Pediatr 1947;31:509.

[3]. Taylor DC, Ounsted C. Boilogical mechanisms influencing the outcome of Seizures in response to fever. Epilepsia1971;12:33

[4]. Fowler M. Brain damage after febrile convulsions. Arch Dis Child 1957;32:67.

[5]. Wallace RH, Berkovic SF, Howell RA, et al. Suggestion of a major gene for familial febrile convulsions mapping to 8q1321. J Med Genet 1996;33:308

[6]. Baram TZ, Shinnar S, eds. febrile seizures. San Diego: Academic Press, 2002

[7]. Knudsen FU, Paerregaard, Andersen R, et al. Long term outcome of prophylaxis for febrile convulsions. Arch Dis Child 1996; 74:13.

[8]. National Institute of Health. Febrile seizures: Consensus development conference summary.Vol.3, no.2 Bethesda, Md: National Institute of Health 1980

[9]. Verity CM, Butler NR, Golding J. Febrile convulsions in a national cohort followed up from birth. II. Medical history and intellectual ability at 5 yrs of age.British Med J 1985;290:1311

[10]. Annegers JF, Blakely SA, Hauser WA, et al. Recurrence of febrile convulsions in a population based cohort. Epilepsy Res 1990;66:1009.

[11]. Berg AT, Shinnar S. Do seizures begets seizures? An assessment of the clinical evidence in humans. J Clin Neurophysiol $1997 ; 14: 102$.

[12]. Consensus statement. Febrile seizure: Long-term management of children with fever-associated seizures. Pediatrics 1980;66:100912.

[13]. Harris R. Iron Deficiency Anemia: does it really matter? Occasional review, pediatrics and child health 2007;17(4)43.

[14]. Parks YA, Wharton BA. Iron Deficiency and Iron deficiency and the brain. Acta Paediatr Scand 1989;361:71-7.

[15]. Millar JS. Evaluation and treatment of the child with febrile seizure. Am Fam Physician 2006;73(10): 1761-4.

Im S, Ah JK, Choi BJ, Lee IG, et al. The Relationship between Iron Deficiency Anemia and Febrile Seizure. J Korean Child Neurol Soc. 2003 May;11(1):55-

[16]. Bidabadi E, Mashouf M. Association between iron deficiency anemia and first febrile convulsion: A case-control study. Seizure.2009 Jun;18(5):347-51. Epub2009 Feb 15. 